\title{
¿De qué hablamos cuando hablamos de servicio público? Notas para un análisis crítico
}

\section{What do we talk about when we talk about public service? Notes for a critical analysis}

Cristóbal Aguilera Medina*

El presente trabajo aborda el concepto de servicio público. Se sostiene que esta figura se estructura sobre presupuestos que son incompatibles con los que subyacen a un sistema subsidiario. Esto se argumenta a partir de un análisis de sus notas determinantes y de una crítica a la teoría según la cual existiría una nueva interpretación de este concepto. Finalmente, se examina el ordenamiento jurídico para reafirmar lo sostenido.

Palabras clave: servicio público, reserva, publicatio, subsidiariedad.
This paper deals with the concept of public service. It is argued that this term is structured over presuppositions that are incompatible with those underlying a subsidiary system. This is based on an analysis of its determining notes and a critique to the theory that argues that there would be a "new" interpretation of this concept. Finally, the legal system is examined to reaffirm what has been sustained.

Keywords: public service, reservation, publicatio, subsidiarity.

\section{Introducción}

No resulta fácil, debido a su volubilidad, referirse al concepto de servicio público (en adelante "s.p.") en la actualidad. Esto contrasta -en principio- con el rol fundamental que jugó esta figura tanto en el origen como en el desarrollo del Derecho Administrativo'. Con todo, el tiempo ha pasado, y los cambios que ha experimentado la manera en que se comprende el fundamento del poder público, el rol de la sociedad civil, el sentido del bien común, entre otros, ha provocado un constante

* Profesor de Derecho Administrativo, Universidad Finis Terrae, Chile. Dirección postal: Av. Pedro de Valdivia 1509, Providencia, Región Metropolitana, Chile. Correo electrónico: caguilera@uft.cl.

1 Silva Cimma 1995, 11.

Artículo recibido el 31 de enero de 2020 y aceptado el 22 de mayo de 2020. 
mutar del sentido de este concepto. A tal punto ha ocurrido esto, que hoy es posible incardinar bajo la noción de s.p. realidades jurídicas que no tienen una significación común: por un lado, los órganos administrativos encargados de satisfacer necesidades colectivas²; por otro, ciertas actividades económicas sujetas a una regulación, como ocurre con la distribución de energía eléctrica ${ }^{3}$.

La posibilidad de denominar s.p. a las dos realidades jurídicas mencionadas tiene como causa la llamada "crisis del s.p.". Esta crisis consistió en la disociación de los elementos de la figura tradicional, que, conforme a la doctrina del s.p. (identificada con el trabajo de la Escuela de Burdeos ${ }^{4}$ ) se entendían como unidad ${ }^{5}$. Esta disociación dio paso a la clásica distinción entre la noción "orgánica" y "funcional" del s.p. ${ }^{6}$. Las razones de esta crisis son múltiples; en el caso de Chile pueden resumirse en la superación del Estado de Bienestar por la irrupción del principio de subsidiariedad, cuyo hito fundamental es la Constitución de 1980. La crisis del s.p., así entendida, constituyó un síntoma de otra crisis mayor, que fue la crisis del Estado de Bienestar.

Estos cambios han provocado cierta desorientación en distintos planos ${ }^{7}$. Consecuentemente, ha habido intentos por explicar el significado del s.p., su relevancia y alcance en un contexto económico que en algunos aspectos es radicalmente distinto del que vio nacer esta figura ${ }^{8}$. Así, son diversos los esfuerzos de desentrañar el significado "actual" del s.p.?.

El presente trabajo busca sumarse a estas reflexiones, que en nuestro país no han tenido la misma intensidad que en otras latitudes ${ }^{10}$. En este sentido, el objetivo primero de estas líneas es reinstalar la discusión en el ambiente nacional ${ }^{11}$. El trabajo seguirá el siguiente esquema: primero abordaremos

\footnotetext{
2 Artículo 28, Decreto con Fuerza de Ley N 1/19.653, de 2001.

3 Artículo 7, Decreto con Fuerza de Ley N² 4/20.018, de 2007.

4 Santofimio Gamboa 2011, 51.

5 Pierry Arrau 2017, 150.

6 ArIÑO OrTIZ 2007, 187.

7 Cassagne 1996, 102; Fernández Rodríguez 1999, 58.

8 En el prólogo a la tercera edición del tomo relativo al s.p. de su obra Derecho Administrativo Chileno y Comprado, Silva Cimma argumenta que "hubo de hacerse una revisión completa de la edición anterior [de 1969], sumamente meticulosa, como consecuencia de que la Administración Chilena, en veinticinco años, ha tenido modificaciones de singular importancia" (SILVA CIMMA $1995,7)$. Estos cambios son la superación de un Estado intervencionista y la instauración de un régimen subsidiario.

9 V.gr. a nivel comparado, Gordillo 2014, CASSAgne 1996, Rebollo 2008, Fernández Rodríguez 1999; Fernández FarReres 2003; a nivel nacional, sugerimos revisar el lúcido trabajo de Vergara Blanco 2004. También podría considerarse Pierry ArRau 2017 y, más recientemente, Rojas CaldeRÓN 2014.

10 Esto explica que las Jornadas de 2019 de la Asociación de Derecho Administrativo de Chile estuvieran dedicadas al tema "el servicio público como actividad". Estas jornadas fueron suspendidas debido al COVID-19.

11 Este trabajo comenzó a escribirse antes del 18 de octubre de 2019. Diferentes diagnósticos se han formulado para explicar la crisis que se instauraría luego de aquel día, entre los cuales se encuentra el que le imputa como causa la "privatización" de los servicios básicos. Esto, a nuestro juicio, vuelve todavía más relevante la tarea de reflexionar sobre la noción de s.p.
} 
las notas determinantes del s.p. Luego, criticaremos la tesis según la cual existiría una interpretación actualizada del s.p. Finalmente, analizaremos el s.p. en nuestro ordenamiento jurídico.

\section{I. ¿De qué hablamos cuando hablamos de servicio público ${ }^{12}$ Dos pun- tos de partida}

Desde sus inicios ${ }^{13}$, que se remontan a los trabajos de los juristas franceses de comienzos del siglo $X^{14}$, el concepto de s.p. ha sufrido múltiples interpretaciones. Así, ha sido calificado de concepto "polivalente"15, "inevitablemente equívoco"16, "que pareciera tener tantas definiciones como autores"17.

Por lo anterior, no es un concepto fácil de abordar. Sin embargo, la tarea de precisarlo es fundamental, en la medida en que no es posible discutir sobre un asunto si no hay claridad sobre el significado de los conceptos, más todavía para el caso de los juristas que trabajan con el lenguaje. En efecto, lo justo e injusto se juzga hablando, es decir, "por medio de la palabra"18. Por esto, "cuando no hay acuerdo en las palabras, se resiente la justicia"19. El acuerdo sobre los conceptos constituye, pues, el punto de partida de todo análisis. De ahí que lo primero sea definir de qué hablamos al utilizar el concepto de s.p., y buscar criterios que sirvan como puntos de partida y que permitan delimitar sus contornos. En lo que sigue nos abocaremos a ello.

Existen diversos esfuerzos por identificar las notas del s.p. ${ }^{20}$. A nuestro juicio, estas pueden condensarse en dos (las demás quedan subsumidas en ellas): la intención de los gobernantes y la reserva de la actividad.

\section{La intención de los gobernantes}

Sin perjuicio de las discusiones conceptuales, pensamos que es posible establecer -a partir de reflexiones de antaño- un criterio formal de identificación que constituya el punto de partida de todo análisis que se oriente a responder jurídicamente la pregunta sobre el s.p.

Este criterio resuelve una tensión que podría ser resumida del siguiente modo: ¿Cuándo hablamos de s.p., hablamos de lo que el legislador estable-

\footnotetext{
12 Este modo de preguntar fue tomado de un interesante texto de Hugo Herrera en el que explica su sentido. Ver HERRERA 2009, 1-6

13 Si bien es cierto, como afirma Valdivia, que los antecedentes de esa noción pueden remontarse a épocas más antiguas, este "recibió su más amplio desarrollo dogmático-jurídico en la doctrina francesa del servicio público" (Valdivia Olivares 2018, 42).

14 A pesar de la discusión sobre la "paternidad" de la teoría del s.p., no cabe duda de que ella se origina en Francia. Ver, v.gr. CASSAGNE 1996, 98.

15 ArIÑO OrTIZ 2007, 18.

16 Fernández Rodríguez 1999, 62.

17 Ibíd., 58.

18 PLATÓN 1966, 1696.

19 Orrego Sánchez 1989, 68.

20 V.gr. Ariño Ortiz 1993, 299-305; Garrido Falla 1994, 21-22.
} 
ce a través de una regulación de derecho público o hablamos de una "esencia" en el concepto que se predica de cierto tipo de actividades (y órganos) con independencia de lo que disponga el legislador? Plantear esta tensión de este modo, tiene por objeto esquivar el riesgo de perder el tiempo con una invención humana, intentando buscar una profundidad metafísica donde no la hay. Así, desde un comienzo, cabe precisar que no hay un significado del s.p. que sea, por así decir, esencial. Esto no significa negar que el concepto esté anclado en premisas filosóficas e históricas, pero, en lo que respecta a sus notas caracterizadoras, no existe algo que le corresponda en esencia, pues sus contornos han sido definidos desde "afuera". En otras palabras, el s.p. no es una realidad natural.

Lo anterior, a pesar de parecer abstracto, es clave tenerlo a la vista desde el comienzo. Cierto autor ha planteado algo similar al criticar el hecho de denominar como s.p. una actividad luego de que el derecho público la ha regulado, pues, esto, más allá de ser intrascendente, lo único que provoca es confusión: alguien podría pensar que esa regulación se establece porque "es" un s.p. en esencia, olvidando que, en realidad, dicha denominación únicamente encuentra su sentido debido a que está regida expresamente por el derecho público ${ }^{21}$.

A partir de lo dicho, y en miras a concretar este criterio formal, podemos remitirnos a un elemento que destaca el jurista francés Gastón Jèze. Frente a la pregunta ¿cómo se reconoce la existencia de un s.p.? o ¿qué circunstancias deben tenerse en cuenta para saber si en un caso determinado existe realmente un s.p.?, Jèze responde que "[a] nuestro entender procede averiguar únicamente la intención de los gobernantes en lo concerniente a la actividad administrativa de que se trate" ${ }^{\prime 22}$. Agrega que "[s]on única y exclusivamente servicios públicos aquellas necesidades de interés general que los gobernantes en cierto país y en una época determinada han resuelto satisfacer por el procedimiento del servicio público" ${ }^{23}$. En el ambiente nacional esto ya ha sido advertido. Se ha afirmado que "hay una idea central que permanece y que puede utilizarse para reconstruir, a partir de ella, la teoría del servicio públi$\mathrm{co}^{\prime 24}$. Esta idea es precisamente la que Jèze identifica bajo la fórmula "intención de los gobernantes", pero aterrizada a nuestro contexto jurídico: "es el Estado, Poder Ejecutivo y Legislativo, para estos efectos, el único juez de las exigencias de interés general, desde el punto de vista de la organización administrativa. Este aprecia libremente si en un determinado momento la satisfacción de interés general debe dar lugar a la creación de un servicio público o debe reconocérsele esa calidad a un organismo o actividad"25.

\footnotetext{
21 GordiLlo 2014, 293.

22 JèZE 1923, 289-290.

23 ĺdem.

24 Pierry Arrau 2017, 105.

25 ĺdem.
} 
En cierto sentido, este criterio es sumamente extensivo (propio de la doctrina francesa) ${ }^{26}$. Por consiguiente, existe el riesgo de vaciar de contenido la noción de s.p., pues la intención del gobernante en miras a satisfacer necesidades públicas puede traducirse en múltiples decisiones. En efecto, si toda determinación en el ejercicio de la función de satisfacer necesidades colectivas consiste en s.p., lo cierto es que la amplitud de este tiende a confundirse con la función misma ${ }^{27}$.

Con todo, este criterio refuerza el punto que ahora intentamos dilucidar, cual es que no existe, a priori, un concepto de s.p. en abstracto, sino que habrá que verificar, en concreto, lo que dispone la ley. Esto no significa que la decisión legislativa no pueda ser objeto de críticas. Sin embargo, los juicios en virtud de los cuales criticamos la determinación sobre el s.p. están "fuera" del concepto, pues no existe un ideal o, si se quiere, un análogo principal del s.p. que sirva como punto de comparación. Así, podemos estar en desacuerdo con que el legislador se abstenga de elevar a rango de s.p. una actividad, pero eso no transforma dicha actividad en s.p.. Igualmente, podemos criticar que una actividad sea definida por el legislador como s.p., pues no satisface necesidades de relevancia social, pero esta crítica no quita que la actividad sea, de hecho, s.p.. Y esto ocurre, pues -insistimos en esto- el s.p. es una invención humana, cuya materialización parte de la premisa de la intención del gobernante. De esta manera, rechazamos la existencia de lo que podría denominarse, en abstracto, el "verdadero" s.p., el s.p. "en estricto sentido", la "esencia" del s.p., etcétera. En palabras de Jèze, "[e]l criterio personal del jurista que resuelve la dificultad es indiferente" 28 .

Conforme a lo expuesto, podemos afirmar que el criterio formal-normativo de la intención del gobernante, es incompatible con dos teorías: la teoría del s.p. virtual y la teoría del s.p. por naturaleza. Cabe, pues, descartar la teoría del s.p. virtual, según la cual "cuando una actividad tiene un claro contenido de interés general, ella constituye s.p. sin necesidad de declaración legal al respecto" 29 . Esto también ha sido advertido por el Tribunal Constitucional, al señalar que "no hay servicios públicos por naturaleza [para nuestros efectos, se debe entender s.p. virtual], pues éstos son una creación del legislador" ${ }^{30}$. Esto tiene diversas consecuencias. Por un lado, implica desechar la idea de Duguit de hacer responsable al legislador por abstenerse de asumir una actividad como s.p., cuando, de no hacerlo, causa trastornos en un país ${ }^{31}$, pues ello significa negar que el s.p. es una definición política. Por otro lado, y relacionado con esto, negar la teoría del s.p. virtual implica

\footnotetext{
26 Jèze sostiene que no es posible dar con un criterio único para poder reconocer la voluntad de los gobernantes a fin de advertir la existencia de un s.p. (JèzE 1923, 291-292).

27 ARIÑO ORTIZ 1993, 294-295.

28 JĖZE 1923, 290.

29 Pierry Arrau 2017, 105-106.

30 Sentencia TC Rol No 1295 (2008), c. 53․

31 Duguit 1913, 127.
} 
también negar que los jueces puedan definir si estamos ante un s.p., cuestión que, en todo caso, ha ocurrido en algunas ocasiones, por ejemplo, cuando la Corte Suprema ha declarado a las Isapres como "servicios públicos desarrollados por particulares" 32 o cuando el Tribunal Constitucional las ha calificado de "servicios públicos sui generis" 33 .

Asimismo, el criterio de la intención del gobernante es incompatible con la teoría del s.p. "por naturaleza", conforme al cual "existirían actividades que naturalmente corresponde ejercer al Estado y otras no" 34-35. Esta teoría supone que solo serían s.p. "aquellos organizados por el Estado teniendo en vista llevar a cabo un acto normal de su función" 36 , esto es, aquellas actividades que corresponden a las funciones que constituyen al Estado, en cuanto que son ejercicio de poder indelegable de la esfera de soberanía, lo cual implica incurrir en una confusión ${ }^{37-38}$.

En definitiva, antes que otro criterio, el primero es uno formal, es decir, uno que se refiere a la forma de identificar (y convertir) algo (órgano o actividad) como s.p., y que es lo que el legislador determina, siendo, por tanto, un asunto fundamentalmente contingente. A continuación, desarrollaremos el segundo criterio que dice relación, ya no con la intención (abstracta) del gobernante, que, en la práctica, se traduce en el establecimiento de un régimen jurídico a fin de satisfacer necesidades públicas, sino con el objeto concreto de esa intención, es decir, el tipo específico de régimen jurídico, que es, si se quiere, el criterio de fondo.

\section{Reserva o captura estatal}

La primera nota del s.p. es que constituye una definición de la intención del gobernante en miras a satisfacer una necesidad colectiva. El segundo elemento es el objeto de esa definición o, dicho de otro modo, lo que significa, en concreto, este modo de intervención que denominamos s.p..

Lo que en concreto significa este modo de intervención es lo que entenderemos bajo el concepto de "reserva". Al usar esta expresión nos referimos a la quinta acepción del Diccionario de la lengua española, según la cual es la "[a]cción de destinar un lugar o una cosa, de un modo exclusivo, para un uso o una persona determinados"39. Otra palabra que también se podría ocupar es "captura". En este sentido, la "cosa" que se reserva o captura es la actividad prestacional que se orienta a satisfacer necesidades colectivas. Lue-

\footnotetext{
32 Sergio Carrasco Delgado con Isapre Consalud S.A. (2010), c. $7^{\circ}$.

33 Sentencia TC Rol N² 2337 (2013), c ${ }^{\circ} 9$.

34 Pierry Arrau 2017, 105.

35 Lo mismo ha criticado cierta doctrina reciente, ver Evans EsPiñeIRa y YÁÑez Rebolledo 2017, 7.

36 Pierry Arrau 2017, 105.

37 Garrido Falla 1994, 11.

38 Armienta Hernández 2013, 89-90.

39 Diccionario de la lengua española, quinta acepción.
} 
go, la "persona determinada" es el Estado. En otras palabras, la reserva nos deja ante una actividad estatalizada ${ }^{40}$.

Esta reserva es denominada por la doctrina como "exclusividad regalística"41. La idea que subyace a este concepto es el monopolio del Estado tanto en la titularidad de la actividad (monopolio de iure) como -en principio, aunque no necesariamente- en la gestión de esta (la exclusividad en la gestión no es determinante, pues puede cederse al particular sin perder la titularidad) ${ }^{42}$. Así, "declarada determinada actividad como servicio público, la titularidad de esa actividad en bloque, es referida a la Administración, con la consecuencia de que en lo sucesivo es una actividad vedada a los particulares" $^{\prime 4}$. El efecto primero de la reserva es, pues, la titularidad estatal ${ }^{44}$.

El efecto necesario de la titularidad estatal es la exclusión de los privados de la llevanza de dicha actividad. Esta exclusión es la primera y principal consecuencia jurídica que interesa al Derecho Administrativo, pues, a partir de ella, se articula el concepto de "concesión de s.p.". En efecto, este concepto supone que hay, como dice su nombre, una cesión por medio de la cual el particular adquiere derecho a realizar una actividad que, en principio, no tenía. Por este motivo (y solo por este) es posible decir que la concesión es un título constitutivo y no meramente declarativo como lo sería la autorización: "[l]la concesión inviste la calidad de traslativa y constitutiva, es decir, son traslativas pues permiten al concesionario ejercer actividades o aprovechar bienes cuya titularidad corresponde a la Administración; pero también son constitutivas, porque otorgan al particular un derecho ex novo del que antes no era titular" 45 . Sin la reserva, entonces, no cabría hablar de concesión, pues no podría cederse nada en la medida en que no se tenga la titularidad de lo cedido.

Desde un punto de vista jurídico filosófico, la reserva encuentra su explicación en la doctrina de la escuela de Burdeos que, en palabras sencillas, comprende la voz "público" que adjetiva el sustantivo "servicio" como sinónimo de "estatal". En resumen, esta teoría supone que el fundamento de la legitimidad del poder público es que el Estado preste cierto servicios a la comunidad" ${ }^{46}$. De ahí que Duguit sostenga que "[l]a noción del servicio público sustituye al concepto de soberanía como fundamento del derecho público" 47 . Esto explica que, conforme a esta teoría, a los particulares solo se les permita

\footnotetext{
40 ArIÑO Ortiz 1993, 286.

41 V.gr. Ariño Ortiz 1993, 300; Fernández Farreres 2003, 10.

42 García de Enterría, en el ámbito municipal, sostiene que "[l]a elevación de los servicios que cita al carácter de monopolio municipal no es más que su elevación al rango de servicios públicos propiamente dichos" (García de Enterría y Martínez-Carande 1955, 117).

43 Guaita Martorell 1969, 67-68. Ver también Ariño Ortiz 1993, 300-301.

44 Garrido Falla 1994, 22.

45 Cordero Vega 2015, 474. Ver también Vergara Blanco 2004, 34.

46 Rodriguez-Arana Muñoz 2013, 63, 69 y 71.

47 Duguit 1913, 93.
} 
colaborar de modo secundario y derivativo, es decir, si así se lo concede la autoridad estatal ${ }^{48}$. En nuestro país esta noción, aunque con ciertos matices, ha sido difundida, de manera que se considera que la relevancia del s.p. está ligada con la intervención del Estado en la vida de interrelación de los particulares: "[e]n la medida, entonces, en que esa administración se realice, y extienda o restrinja su esfera de acción, es que adquirirá mayor valor o lo perderá la teoría general del servicio público. Todo esto se vincula, en definitiva, a la extensión mayor o menor que se comete a la gestión del Estado" 49.

\section{La publicatio como concepto paradigmático}

El concepto que se emplea para referirse a la acción y efecto de reservar, para referirse a la intención del gobernante de "elevar" a s.p. una actividad, es el de publicatio ${ }^{50}$. Etimológicamente hablando, publicatio significa "hacer público"51. Este concepto tiene, de la mano de lo recién dicho, una doble dimensión. Por un lado, significa que la prestación de la actividad definida como s.p. "la ley ha puesto a cargo de un determinado organismo público estatal" 52 . Por otro lado, supone que el encargo es excluyente. Esto es que la actividad que se ha incorporado al quehacer del Estado es ejercida de manera reservada, asumiendo la titularidad y quedando fuera de la actuación espontánea de los particulares ${ }^{53}$. Aun si se acepta que la publicatio admite diversas modalidades, en todas ellas (reserva intensa o media) "el Estado asume como tarea propia la gestión de la actividad reservada, solo que en el primer supuesto lo hace directamente, mientras que en el segundo lo hace de manera indirecta" 54 . Por esto, desde que se acuñara el concepto de publicatio (mediado del siglo XX), se comprendió como una técnica que se orienta a la creación de "títulos ope propietatis de potestad sobre actividad privada"55. De ahí que la reserva sea "hecha, ciertamente, de la primacía de la iniciativa privada y del principio de subsidiariedad" 56.

La publicatio es, por tanto, en cuanto elemento de un modo específico de intervención (s.p.), lo determinante de ese modo. Por ello, frente a la pregunta "¿de qué hablamos cuando hablamos de s.p.?", podemos respon-

\footnotetext{
48 Vergara Blanco 2004, 33.

49 Silva Cimma 1995, 12.

50 La palabra es de origen romano. Con todo, en el Derecho Romano no hay una única manera de entenderla. Sin embargo, lo que sí nos parece claro -hasta donde hemos podido examinar-, es que el concepto publicatio, en cuanto actuación de la autoridad pública, operaba respecto de bienes y no respecto de servicios. De ahí que la aplicación sobre servicios sea un invento que es atribuible al trabajo de Villar Palasí. Ver: Bassols coma 1977, 47.

51 Sustantivo público y sufijo tio(n), que significa acción o efecto. En el Diccionario de la lengua española, la palabra cuya raíz latina es publicatio o publicationis es el sustantivo publicación (verbo transitivo publicar, de raíz latina publicare).

52 SOto KLOSS 2012, 567

53 Vergara Blanco 2004, 40.

54 Hernández González 2002, 150-151.

55 BASSOLS COMA 1977, 47.

56 Soto KlosS 2012, 567.
} 
der que hablamos, fundamentalmente, de la publicatio. Sin la publicatio no podemos hablar de s.p., como tampoco de aquello que se deriva de este, como la distinción entre concesión y autorización, pues no existiría el elemento en virtud del cual la distinción es posible. De ahí que sostengamos que es el concepto paradigmático. Ahora bien, también es paradigmático por otro motivo: porque logra condensar la doble dimensión del s.p.. Como quiera que la publicatio es estatización de una actividad, ello implica que solo el Estado puede llevarla a cabo. Así, la perspectiva material se funde con la perspectiva orgánica: solo los servicios públicos (órgano) pueden llevar a cabo servicios públicos (actividad).

\section{Evolución de una idea}

Al comienzo del Libro Segundo de "Los principios generales del Derecho Administrativo", Gastón Jèze afirma que "[e]n todos los países civilizados satisface la Administración necesidades de interés general" 57 . Luego, reconoce que hay diversos modos de satisfacer estas necesidades, y que su elección depende de decisiones políticas. Así, reconoce, en general, dos modos: el procedimiento de derechos privado y el procedimiento del s.p.. El procedimiento del s.p. caería dentro de aquel en virtud del cual "Administración está encargada de satisfacer con exclusión de los particulares" 58 .

Lo dicho por Jèze, aunque parece obvio, es de suma importancia. A la hora de aproximarse al tema del s.p., antes de analizar en específico este tipo de intervención, da un paso atrás, para advertir que el s.p. es un modo, entre otros, de conseguir el fin de satisfacer necesidades colectivas. Este sencillo ejercicio es clave, pues es usual que se confundan las características del s.p., en cuanto modo específico de intervenir, con el fin público de satisfacer necesidades colectivas. Ambas cosas, por cierto, no son lo mismo, y la confusión en que se incurre no es trivial. Veamos.

\section{Un "nuevo" concepto de servicio público}

Al comienzo hemos sostenido que el acuerdo sobre el significado de los conceptos constituye el punto de partida de cualquier análisis. En este sentido, un riesgo que se corre es pretender conseguir "la uniformidad al precio de distorsionar el concepto jurídico" 59 . Esto es lo que ocurre cuando se busca incardinar dos realidades diversas bajo un mismo concepto. En lo que se refiere al s.p., cierta doctrina ha pretendido reinterpretarlo a partir de críticas a la noción original. En lo fundamental, se ha sostenido que ella no responde a los cambios experimentados en las sociedades en cuanto a la dirección de su desarrollo. Estas críticas no buscan eliminar el concepto, sino "adecuarlo" a la realidad actual. La idea -errónea, según veremos- que subyace a esta

\footnotetext{
57 JèZE 1923, 283.

58 ĺdem.

59 Orrego Sánchez 2019, 92.
} 
pretensión, es mantener vigente el concepto ${ }^{60}$, dándole continuidad bajo una "nueva" perspectiva.

El fenómeno que más ha impactado en la idea de configurar un "nuevo" s.p. ha sido la privatización ${ }^{61}$. La privatización significó la transferencia de la titularidad de una serie de servicios desde el Estado a los particulares, es decir, operó una des-publicatio. Esto provocó un vuelco tanto en la labor que comenzaron a asumir los particulares en relación con ciertas actividades que satisfacen necesidades colectivas, como en la actividad específicamente de policía que asumió el Estado (potestades de fiscalización y de sanción).

El fenómeno descrito fue el antecedente del denominado Derecho Regulatorio ${ }^{62}$. El Derecho, en este ámbito, justifica la intervención del Estado en la actividad económica en dos objetivos: primero, "garantizar la prestación presente y futura del servicio de que se trate"; segundo, "establecer los niveles adecuados en la relación calidad-precio, según el grado de desarrollo y las prioridades que cada sociedad quiera establecer"63. De ahí que se haya acuñado el concepto de "mercados regulados", para aludir a una intervención más intensa del Estado, que se traduce en la imposición de cargas a los particulares tanto en el acceso, permanencia o retiro de actividades económicas $^{64}$. Sin embargo, al ser actividades económicas, la intervención del Estado solo se limita a la regulación y fiscalización ${ }^{65}$. No puede, en efecto, operar una reserva, dado el derecho a la libertad económica. En otras palabras: la esfera de la libre iniciativa de los privados no puede ser reducida en el sentido de que el Estado acapare alguna actividad económica. Este es uno de los efectos más fuerte en el ámbito económico del principio de subsidiariedad. Lo que establece específicamente la legislación chilena lo veremos más adelante. Lo que ahora nos interesa es examinar la propuesta de un nuevo concepto de s.p., bajo la idea de adecuarlo al marco jurídico actual que parte de la premisa de que estas actividades están abiertas a la competencia ${ }^{66}$.

Entre los esfuerzos que se han realizado con este fin, se encuentra la tesis según la cual la noción "actualizada" del s.p. constituiría "en cuanto a fenómeno material y jurídico (...) un Derecho de regulación de actividades económicas donde están involucrados intereses generales o colectivos -o sea, de toda la población o de alguna parte de ella- y en definitiva públicos, identificando la noción de servicio público con una técnica legal de regulación

\footnotetext{
60 Este es el esfuerzo que inspira el importante trabajo de Silva Cimma y, específicamente, su tesis de que el s.p. aún mantiene su vitalidad (Silva Cimma 1995, 74-51).

61 Aróstica Maldonado 1995, 259-261.

62 Cordero Quinzacara 2013, 120.

63 Ariño Ortiz 2003, 589. Ver también: Cordero Quinzacara 2013, 121-122.

64 Las exigencias se traducen en el cumplimiento de lo que se denomina principios de operación. Para el caso de la regulación de la energía eléctrica, ver: Evans EsPIÑERIA y YÁnez Rebolledo 2017, 8-10.

65 Cordero Quinzacara 2013, 122-125.

66 Vergara blanco 2004, 37.
} 
sobre actividades de contenido económico cuya titularidad ostenta la Administración pública o no, y su gestión es realizada fundamentalmente por particulares, destinadas a la satisfacción de necesidades generales o sectoriales colectivas"67. Lo importante de esta definición es la expresión "o no", pues ello cambia "el eje central desde la titularidad estatalizada a la del régimen jurídico, constituyéndose en verdadero Derecho de la regulación de actividades económicas -como se dijo anteriormente-, que desplaza el régimen de actividad administrativa de prestación, y que debe atender intereses de toda la población"68. Una idea similar fue sostenida por otra doctrina, según la cual, si determinados servicios son gestionados por particulares en condiciones monopólicas, el "Estado debe ejercer su potestad de controlar cómo se presta ese servicio. Allí reaparece un corpus normativo y una realidad económica que puede ser calificada últimamente como servicio público"69.

Este esfuerzo busca conciliar la noción tradicional del s.p. con un marco normativo donde se privilegia la iniciativa privada. Con todo, esta idea presenta tres problemas. Primero, nos parece que se cae en la distorsión de conceptos que más arriba mencionamos. Si el s.p. es el régimen de reserva estatal, pero también es el régimen de mercado regulado, entonces denominamos bajo el mismo concepto situaciones jurídicas conceptualmente opuestas (transgredimos la distinción básica formulada por Jèze). Y no cabe la argumentación de que el concepto se debiera interpretar conforme a la evolución económica, con el fin de actualizarlo. Una interpretación que le asigna a un concepto una significación que es opuesta a la original, en rigor, no es una interpretación, sino un cambio en su sentido y alcance. Estamos, pues, ante dos figuras diferentes, que debieran ser conceptualizadas, como es lógico, de modos diferentes, más aún cuando sus presupuestos son incompatibles (lo veremos). Una pretensión similar es la de actualizar el concepto de publicatio para hacerlo coincidir con la decisión estatal, no de capturar, sino de "que una actividad se sujeta a las potestades administrativas mediante un régimen especial"70. De este modo, el Estado no sería titular de la actividad, sino que titular "de la regulación del servicio público"71. Pero, de igual modo, se tuerce el sentido de las palabras.

La segunda objeción, dice relación con el tipo de actividad de que se trata. Conforme a la tradicional distinción, las actividades de la Administración son fomento, servicio público y policía ${ }^{72-73}$. Tomando de nuevo las palabras de Jèze, cabe decir que todas estas actividades se orientan a satisfacer necesida-

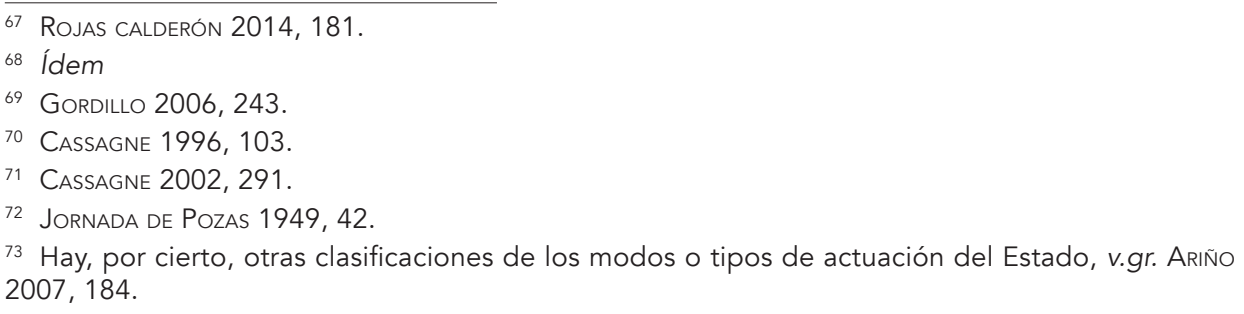


des colectivas, por lo que todas ellas, en cierto sentido (en un sentido general, que no aporta mayor significación), son s.p., pues a toda subyace la idea de que el "[e]l derecho administrativo propende a la satisfacción de necesidades públicas"74. Pero, materialmente, es decir, sin perjuicio de que coincidan en la causa final, son actuaciones diferentes. En este caso, bajo la tesis de la actualización del s.p., la actuación del Estado es la de "regular", es decir, crear un estatuto normativo al que los particulares deben someterse en la medida en que desarrollen la actividad que dicho estatuto regula. Materialmente esta no es una actividad de s.p., dado que no es una actividad prestacional.

Lo que cierta doctrina denomina "nuevo s.p." es, en realidad, actividad "legislativa", ya que consiste en la "emanación de normas obligatorias"75, que corresponde inicialmente al legislador y, luego, en su concreción, a la Administración. En otras palabras, es la intervención del Estado "para regular las actividades económicas por razones de interés público"76, interés que, en este caso concreto, apunta a la satisfacción de necesidades colectivas ${ }^{77}$. A su vez, la actividad de velar por el cumplimiento de estas normas obligatorias es una actividad de policía, es decir, una actividad de la Administración "realizada en el ejercicio de su potestad pública, que supone la limitación de los derechos de los particulares, por razones de interés general y con el objeto de alcanzar la mantención del orden público"78. También se ha definido policía como "el conjunto de medidas coactivas arbitradas por el Derecho para que el particular ajuste su actividad a un fin de utilidad pública"79. Esta última es una definición, que, si bien es "provisional", de todos modos es útil, pues enfatiza en la idea de "ajuste de actividad a un fin de utilidad pública". Específicamente, podría adoptarse la nomenclatura de "policía especial", pues constituye un "conjunto de medidas limitativas de la actividad de los particulares que se dictaron en específicas materias" 80 . Así, coincidimos con un autor que sostiene que es un error comprender la actividad regulatoria como una "modalidad de la actividad de la Administración"81, ya que esta puede comprenderse bajo las categorías tradicionales de actuación.

Es importante aclarar esta confusión, no solo por los eventuales efectos prácticos, sino que también por los desafíos conceptuales del Derecho Ad-

\footnotetext{
74 Valdivia Olivares 2018, 41.

75 JoRnAda de POZAS 1949, 42.

76 Cordero Quinzacara 2013, 120.

77 La regulación presenta características que responden a lógicas de la noción tradicional del s.p., como la continuidad del servicio (Duguit, por ejemplo, trataba la continuidad como un aspecto fundamental (ver Duguit 1913, 103). Sin embargo, ello solo representa una manifestación de la figura tradicional en "un mundo en el que la publicatio ha caído en desuso a causa de la entrada de los conceptos de competencia y libertad económica en muchas actividades en el pasado calificadas de servicios públicos en sentido estricto" (Rodríguez-Arana Muñoz 2013, 64.)

78 BeRMúdez 2014, 319.

79 Garrido Falla 1953, 11.

80 Ídem. Ver también Bermúdez 2014, 320.

81 Cordero Quinzacara 2013. 123-124.
} 
ministrativo. El autor que postula la tesis que criticamos, con todo, sostiene que este régimen o actividad "es fundamento y explicación, ya no del Estado de Policía ni Estado del Bienestar, sino de un Estado garante de intereses públicos frente a la actividad de empresas privadas que funcionan en régimen de mercado y competencia en aquellos sectores que tienen relevancia para la sociedad y sus habitantes, y garantizando que en ellos se realicen prestaciones básicas conforme reglas o principios mínimos de operación" ${ }^{\prime 2}$. Con todo, a esto podemos responder que la asunción del Estado de una posición de garante no es incompatible con que dicha posición se realice a través de actuaciones de policía (especial), como ocurre, por ejemplo, con el deber preferente del Estado de garantizar la ejecución de las acciones de salud ${ }^{83}$.

En tercer lugar, nos parece que también hay un problema en la tesis que ahora comentamos al confundir los conceptos de publicatio y publificación, que la doctrina, en general, suele comprenderlos como sinónimos. Publificar significa "trasladar la regulación de una determinada actividad desde el derecho privado al derecho público" 84 . En este sentido, se ocupa el concepto para describir el fenómeno -cada día más importante- de la "publificación del derecho privado" 85 . En consecuencia, no todo traslado de la regulación de una actividad desde el derecho privado al derecho público supone necesariamente que la autoridad administrativa asume la titularidad de esta actividad. En otras palabras, no toda publificación implica una publicatio. Hay una confusión entre el género y la especie, cuestión que también nos parece que ocurre en el intento de "actualizar" la noción de la publicatio que revisamos líneas arriba.

En este punto, nos parece interesante destacar el argumento de un autor en miras a mantener la categoría del s.p. y, concretamente, de la publicatio, aun en un contexto jurídico subsidiario. En síntesis, este autor se opone a la tesis de "abandonar la idea de la publicatio específica para reemplazarla por una noción ambivalente 0 , si se quiere, polifacética, como es la noción de regulación económica" 86 . La razón fundamental de esta oposición, es que, a pesar de los cambios descritos, "seguirá siendo necesario distinguir -en el campo de la regulación económica- los servicios públicos de las llamadas actividades de interés público, porque el problema que plantea la naciente realidad no se resuelve con la unificación de todas las regulaciones, sino más bien con el reconocimiento de la especialidad y diversidad que posee el

\footnotetext{
82 ROJAS CALDERÓN 2014, 181.

83 El inciso cuarto del numeral 8 del artículo 19 de la Constitución establece que "[e]s deber preferente del Estado garantizar la ejecución de las acciones de salud, sea que se presten a través de instituciones públicas o privadas, en la forma y condiciones que determine la ley, la que podrá establecer cotizaciones obligatorias". Así, el Estado garantiza la prestación de acciones de salud "a través de instituciones privadas", prestación que, en consecuencia, deberá regular, regulación a la cual el particular deberá someterse ("en la forma y condiciones que determine la ley"). Esto ocurre, por ejemplo, en el caso de los convenios celebrados entre los Servicios de Salud e instituciones privadas en virtud del Decreto con Fuerza de Ley Nº 36 de 1980.

84 Diccionario de la lengua española, segunda acepción Der.

85 GuZMÁn Brito 2015, 20-21.

86 Cassagne 1996, 104.
} 
servicio público, en relación con otras actividades de interés público que no se imponen como prestaciones obligatorias" 87 . Sin perjuicio de compartir la distinción entre los tipos de actividades que se exponen, nos parece que su razonamiento es equivocado en la medida en que basta revisar la regulación específica para saber si la actividad, por satisfacer necesidades colectivas, se debe realizar de manera continua y regular, imponiéndole al particular, en consecuencia, una carga pública de esa naturaleza (ahondaremos en esto).

\section{Servicio público: ¿una técnica, solo una técnica? ${ }^{88}$}

Lo expuesto en el apartado anterior nos acerca a una cuestión decisiva en esta reflexión sobre el s.p., que dice relación tanto con la determinación de sus elementos como con la distinción respecto de otros modos de intervención estatal. Hemos sostenido que el s.p. es una técnica caracterizada por la reserva estatal de la actividad prestacional. Con todo, si bien es cierto que, en abstracto, constituye una "alternativa" entre varias de que dispone el Estado para satisfacer necesidades colectivas, no se puede analizar simplemente como una técnica y solo una técnica más.

Desde un punto de vista, los modos de intervención estatal pueden diferenciarse según su "intensidad". En efecto, por decirlo así, se puede advertir intervenciones de mayor o menor fuerza, es decir, mayor o menor presencia. Así, que el Estado regule una actividad que desarrolla un particular es menos intenso que el que el Estado asuma la titularidad de esta. Con todo, desde otro punto de vista, que dice relación, en último término, con la concepción del Estado y sus fines, el criterio de intensidad no logra captar lo que subyace a la definición del s.p., pues lo que existe es más bien una opción política que se relaciona -según sostuvimos- con las diferentes formas de entender el fundamento de la legitimidad del poder público.

En este marco, la publicatio (como nota central de la noción tradicional del s.p.) y la publificación de actividades económicas ("nuevo" s.p.), no corresponden al mismo género de intervención, pues las lógicas detrás de ambos no tienen punto en común. La publicatio, que significa acaparamiento estatal, con la consecuente supresión de la iniciativa privada en ese ámbito económico particular, supone la idea de que el Estado está llamado primera y privativamente (in iure) a la satisfacción de aquellas necesidades que se cubren por medio de dicha actividad. Esta premisa pugna con el principio contrario a esta tesis, que es el principio de subsidiariedad, el cual fundamenta o, más bien, es el antecedente desde el cual se articula la noción "actualizada" del s.p.. Este principio admite grados de intervención (por ejemplo, es compatible con este principio que el Estado asuma un rol activo en la garantía y prestación directa), pero es incompatible con un régimen de reserva. Y

\footnotetext{
87 Ibíd., 104-105.

88 Este título está sacado del apartado II, "Una técnica, solo una técnica", del lúcido artículo "Del servicio público a la liberalización desde 1950 hasta hoy" de Tomás-Ramón Fernández (FERNÁNDEZ RODRÍGUEZ 1999, 59).
} 
esta incompatibilidad encuentra su causa en el hecho de que la publicatio vulnera el principio de la primacía de la persona humana ${ }^{89}$ (la dignidad de la persona humana es el fundamento de la subsidiariedad ${ }^{90}$ ), en cuanto a que ella y las organizaciones que articule en el despliegue de su libertad asociativa (sociedad civil), son los primeros llamados a satisfacer las necesidades colectivas, ya que "la persona es responsable primigenio del bien común cuya contribución al mismo tiempo no es solo un deber sino un derecho inalienable, porque es, al mismo tiempo, fuente de su propia perfección y expresión de su dignidad"91. Puesto así, la reserva y la regulación no pertenecen al mismo "género" de intervención, ya que bajo un criterio que tome en cuenta las lógicas que subyacen a estas actuaciones, es claro que se fundan en criterios de legitimidad del Estado que son contrarios entre sí.

\section{Dialéctica entre Estado y sociedad: un problema de relación y de poder}

Es usual que se sitúe la reflexión teórica sobre el s.p. en un tema que podría condensarse bajo la idea de la dialéctica entre el Estado y la sociedad. Esto se debe, principalmente, al hecho de que "[l]a separación entre Estado y sociedad pertenece al interior del propio Estado, y es privativa del pensamiento político moderno. El Estado es la forma de lo político en cuanto concebido como autónomo respecto de lo social. La sociedad es la forma de lo social en cuanto concebido como autónomo respecto de lo político"92. En palabras de otro filósofo, podríamos decir que la dialéctica a la que se alude para enmarcar la reflexión del s.p., nace de la idea de que la noción de Estado moderno introdujo separaciones fundamentales, entre las cuales está la "separación de la sociedad civil y el Estado"93.

El Estado moderno se identifica con la idea de la condensación del poder político y, en consecuencia, de que todo ejercicio de poder "procede, como delegación, de una sola fuente que lo monopoliza"94. De ahí que, desde la Revolución Francesa -momento en el cual nace el Derecho Administrativo- "la Administración Pública se identificara con el Poder ejecutivo" 95. Sumado a lo dicho, hay que advertir que en el contexto histórico en que nace la figura primaba la tesis de que "las tareas del Estado y las tareas de la sociedad son tareas diferentes"96. En este cuadro conceptual, es fácil comprender la idea de la dialéctica: el s.p. "constituye una técnica instrumental que, como categoría histórica, traduce una dialéctica entre Sociedad y Estado"97.

\footnotetext{
89 Soto Kloss 2002, 44 y 48.

90 URBINA Molfino 2005, 326-331. Para mayor desarrollo de la fundamentación antropológica de la subsidiariedad, ver FINNIS 2000, 174-176.

91 Arancibia MatTAR 2017, 3.

92 Cruz Pradros 2006, 53.

93 MANent 2016, 39.

94 Cruz Prados 2006, 53.

95 García de Enterría y Martínez-Carande y Fernández Rodríguez 2006, 28.

96 Ariño Ortiz 1993, 286.

97 Cassagne 1996, 98.
} 
Esta dialéctica, sin embargo, luego de que se materializaran los cambios políticos y económicos que hemos relatado brevemente más arriba (privatización), ha quedado fuertemente matizada. En efecto, la idea de la libre iniciativa de los particulares configura un orden social diverso al anterior, pues estos pueden realizar actividades que antes estaban reservadas al Estado. El Estado, de este modo, pierde la potestad de capturar, y los particulares no necesitan, en consecuencia, de una delegación de poder para realizar cierto tipo de actividades. Así, la noción jurídica de concesión, con toda la fuerza doctrinal que condensa, queda al margen de un sistema jurídico que no permite la reserva estatal. En este sentido, en la medida en que se establece un régimen abierto a la competencia, se adopta un orden social que es incompatible con el s.p.. En otras palabras, si la publicatio, como elemento determinante del s.p., implica -como hemos mencionado- "una reserva hecha, precisamente, de la primacía de la iniciativa privada y del principio de subsidiariedad" 98 y, a la vez, si estos principios y derechos no pueden ser vulnerado, se puede comprobar la incompatibilidad a que aludimos.

Esto no quiere decir que el Estado queda al margen del fin público de satisfacer necesidades colectivas. La subsidiariedad no supone ausencia, ni tampoco mera suplencia o sustitución, como algunos autores han sugerido ${ }^{99}$. Como hemos visto, al Estado sí le cabe, en cuanto a su labor específicamente subsidiaria (faz positiva ${ }^{100}$ ), establecer una regulación (y fiscalizar su cumplimiento) para el correcto desenvolvimiento de las actividades que satisfacen necesidades colectivas. En este sentido, estas actividades económicas, en la medida en que son reguladas en miras al fin mencionado, contribuyen a crear y proveer bienes que son "públicos" (comunes). Esto es así, pues los bienes que existen en comunidad no son públicos o privados según el sujeto que los produce o distribuye (Estado o particular), sino por el modo en que estos se comparten, y la regulación, en el caso de los bienes públicos, busca justamente que ellos se compartan públicamente, es decir que "cada uno participa de él en virtud de su condición de miembro del pueblo, de ciudadano"101. Con todo, esta regulación supone -como hemos sostenido- la libertad económica, la que es incompatible con el s.p.. Y esta incompatibilidad, lo veremos ahora, es la que existe en nuestra legislación.

\section{Servicio público en el ordenamiento jurídico chileno}

Hemos adelantado al comienzo que la legislación chilena distingue dos significados del concepto de s.p.: orgánico y material. Esto ya nos advierte de un dato relevante, cual es que la unidad que supone el concepto original no aplica en nuestra legislación. Esto se comprueba, además, si se observa que

\footnotetext{
98 Soto Kloss 2002, 567.

99 Para una argumentación acerca de que subsidiariedad no es equivalente al acto de suplir o reemplazar, ver LETELIER WIDOW 2015, 115-119.

100 Millán-Puelles 2000, 144-154.

101 CRUz PRADo 2009, 98.
} 
la Administración no realiza ninguna actividad prestacional de modo excluyente y, a la vez, que los particulares realizan actividades de estas características sin necesidad de una concesión (esto lo veremos enseguida).

No es nuestro objetivo hacer un análisis normativo minucioso, sino tomar ciertos elementos que nos parecen relevantes a la hora de reflexionar sobre el s.p.. Para ello, se distinguirá el análisis desde el punto de vista orgánico y material.

\section{Servicio público como órgano}

Todas las menciones del concepto s.p. en la Constitución aluden a la noción orgánica. Lo mismo ocurre con la Ley $N^{\circ} 18.575$. Esto ya da luces acerca del énfasis de la perspectiva orgánica en nuestra legislación, conforme a la cual s.p. serían las "entidades de que el Estado se vale para cumplir su política de satisfacer necesidades públicas"102. Esto ha significado que cierta doctrina concluya que, desde el punto de vista normativo, "prima por entero en nuestro derecho el servicio público orgánico"103.

El artículo 3 de la Ley $N^{\circ} 18.575$ norma el fin de la Administración, cual es la promoción del bien común "atendiendo las necesidades públicas en forma continua y permanente". Por su parte, el artículo 28 dispone que los servicios públicos son "órganos administrativos encargados de satisfacer necesidades colectivas, de manera regular y continua". La conceptualización es sumamente amplia, pues, por un lado, estos servicios públicos no solo realizan actividades de prestación, como originalmente se comprendía la noción de s.p., sino también realizan otro tipo de actividades en donde la Administración "queda fuera de la gestión"104. Por nombrar dos casos, la Corporación Nacional de Desarrollo Indígena tiene importantes funciones de "promoción" o "incentivo"105, que no son prestacionales. Lo mismo cabe decir de la Dirección del Trabajo, cuya labor es, fundamentalmente, de fiscalización ${ }^{106}$, donde no se aprecia una actividad de prestación. Dicho de otro modo, hoy los servicios públicos-órganos no realizan, necesariamente, servicios públicos-actividad.

Además de lo dicho, cabe aclarar que estos servicios públicos, si bien muchos de ellos realizan materialmente actividades de prestación, ello no lo hacen de modo reservado, pues no ha operado la publicatio. Por ello es un error comprender que el artículo 37 de la Ley $N^{0} 18.575$ trata de actos de naturaleza concesionaria. En efecto, por un lado, esta disposición utiliza el vocablo "encomendar", cuyo sentido es muy distinto al de "concesionar"; este último supone que quien concede tiene la titularidad de lo concedido, no así

\footnotetext{
102 Silva Cimma 1995, 48.

103 ĺdem.

104 ArIÑO Ortiz 1993, 299.

105 Artículo 38 y 39, ley N 19.253, de 1993.

106 Artículo 1, Decreto con Fuerza de Ley N², de 1967.
} 
en el caso del verbo encomendar. Por otro, las veces en que la legislación regula la aplicación de este artículo, reafirman este aspecto.

Un ejemplo de esto último son los convenios que celebran los Servicios de Salud con instituciones privadas. De acuerdo con el artículo 37 citado y según lo dispone el artículo 23 letra i) del Decreto con Fuerza de Ley $N^{\circ} 1$ de 2005 del Ministerio de Salud, se autoriza a los Directores de los Servicios de Salud a celebrar convenios "con toda clase de personas naturales o jurídicas [por ejemplo, instituciones privadas de salud], a fin de que tomen a su cargo, por cuenta del Servicio, algunas acciones de salud que a éste correspondan por la vía de la delegación o de otras modalidades de gestión". En este sentido, la institución que ha celebrado el convenio "sustituye" al Servicio en la ejecución de las acciones objeto del acuerdo ${ }^{107}$. El convenio, con todo, no implica una concesión, puesto que las acciones de salud que el Estado encarga no le están reservadas. En efecto, el artículo 3 del Decreto con Fuerza de Ley mencionado dispone que las instituciones privadas "gozan de la libre iniciativa para realizar acciones de salud, en la forma y condiciones que determine la ley". Por este motivo, el Tribunal Constitucional, al declarar la inconstitucionalidad del inciso segundo del artículo 13 del Decreto Supremo N 67 de 2018 del Ministerio de Salud, que prohibía que las instituciones privadas que suscriban convenios con el objeto de ejecutar cierto tipo de prestaciones puedan ser objetores de conciencia, argumentó, en contra de lo que sostuvo la Contraloría General de la República108, que el Estado "garantiza ampliamente la libertad de asociación, y permite iure proprio a las instituciones privadas participar en el quehacer de la salud"109. En este sentido, declaró que la figura de la concesión de s.p., de acuerdo con la Escuela de Burdeos, se estructura en torno a "[s]upuestos que, como es posible advertir, no son del todo compatibles con el derecho público chileno, que parte por el deber del Estado de reconocer y amparar a los cuerpos intermedios de la sociedad"110-111.

\section{Servicio público como actividad}

Antes nos hemos referido a la tesis de que la noción del s.p. "actualizado" es un derecho de regulación de actividades económicas donde está involucrado el interés general, destinada a satisfacer necesidades colectivas. Con el fin de aclarar el panorama, el autor distingue cuatro figuras: servicios públicos estatales, servicios públicos concedidos, servicios de utilidad pública o mercados regulados y servicios privados de interés públicos o servicios públicos impropios (virtuales) ${ }^{112}$. Luego, enumera una serie de principios que serían apli-

\footnotetext{
107 Esta es la expresión que utiliza el artículo 2 del Decreto con Fuerza de Ley N³6, de 1980.

108 Dictamen N 11.781 (2018); Dictamen N² 24.216 (2018).

109 Sentencia TC Rol No 5572 (2018), c. $18^{\circ}$.

110 ĺdem.

111 Para un contrapunto a esta sentencia, ver CoRDERO VEGA 2019.

112 ROJAS CALDERÓN 2014, 181-182.
} 
cable a todas estas categorías, que constituirían los "servicios públicos lato sensu"113. Estos principios son la universalidad, la continuidad, la igualdad y no discriminación y la mutabilidad ${ }^{114}$.

La distinción, con todo, nos parece más compleja de lo que la realidad normativa nos ofrece. Por un lado, ya resulta a lo menos problemático denominar a todos los casos señalados bajo el vocablo s.p., teniendo en cuenta las prevenciones conceptuales que más arriba hemos formulado. Así, por ejemplo, los servicios públicos estatales, que el autor adjetiva con la expresión "propiamente tales"115, en realidad no tienen como característica determinante la publicatio, por lo que no podrían ser, en realidad, s.p. propiamente tales. Por otro lado, los servicios de utilidad pública y servicios privados de interés público responden a una misma lógica: actividades económicas que los privados pueden libremente desarrollar en la medida en que cumplan con las disposiciones que la ley establece. La regulación, por cierto, se debe a razones públicas. En este sentido, los -denominados por el autor-mercados regulados (o servicios de utilidad pública, aunque este concepto no coincida con el que la Constitución utiliza), como el caso de la electricidad, no son fundamentalmente distintos de aquellos -como también denomina el autorservicios privado de interés público, como el caso de los servicios de taxis. En ambos casos se imponen cargas públicas a quien ejecuta la actividad. En otras palabras, en ambos subyace la misma lógica, cual es el ser actividades económicas que los privados pueden desarrollar libremente, cumpliendo con las condiciones que establece la ley (lógica autorizacional). Esto es así, además, si se advierte lo que el autor señala, de que ambas deben regirse por los principios mencionados en la prestación de estos servicios (la diferencia que existe es, pues, sobre el tipo de carga pública específica que se impone).

Finalmente, la denominación de servicios públicos concedidos, también nos parece errónea, pues, si bien es cierto que puede existir una delegación o encargo, la actividad que se encarga no está reservada a la Administración. En este sentido, no hay, en estricto rigor, una concesión; hay una relación jurídica que se establece, pero lo fundamental en este caso no es la titularidad de la actividad. Por último, cabe decir que "los servicios de utilidad pública o cuya paralización cause grave daño a la salud, a la economía del país, al abastecimiento de la población o a la seguridad nacional" (inciso quinto del artículo $19 \mathrm{~N}^{\circ} 16$ de la Constitución) tienen una característica propia que es la prohibición de huelga que se sigue de la importancia de estas actividad, lo cual, en todo caso, la misma disposición señala que debe estar regulada por ley, por lo que deberá estarse a lo dispuesto en concreto. Aquí se advierte, como se ha señalado, una característica clásica del s.p., que es la continuidad y regularidad ${ }^{116}$, pues la paralización del servicio es altamente perjudicial para

113 Ibíd., 181.

114 Ibíd., 182-185.

115 Ibíd., 181

116 Duguit 1913, 103; Cassagne 2002, 304 
la sociedad. Con todo, ello no significa que deban ser comprendidas como s.p.: no hay publicatio.

Lo anterior es importante prevenirlo, pues, a nuestro juicio, la distinción fundamental o, por ocupar la expresión de un autor, la summa divisio, ya no es entre actividades económicas reservadas y no reservadas ${ }^{117}$, sino que entre actividades económicas reguladas y no reguladas. Esto es así, pues bajo los presupuestos jurídicos actuales, la dicotomía debe dejar fuera la consideración fundamental del s.p., que es la reserva. La razón de esta exclusión, desde el punto de vista normativa, es que el artículo $19 \mathrm{~N}^{\circ} 21$ excluye la publicatio. En efecto, reconoce dicho numeral el "derecho a desarrollar cualquier actividad económica que no sea contraria a la moral, al orden público o a la seguridad nacional". Esto es una concreción en materia económica del principio de la primacía de la persona humana ${ }^{118}$. A la vez, el mismo numeral establece: "respetando las normas legales que la regulen". Es decir, el Estado puede regular las actividades económicas, con el fin, por ejemplo, de que ellas se presten de manera regular y continua pues son funcionales a satisfacer necesidades públicas (sector eléctrico) o porque su desarrollo puede causar daños a terceros (farmacia), al medio ambiente o abusos (bancos), etcétera. Es decir, es la regulación, de la mano del ejercicio de la actividad de policía, la forma que tiene el Estado -más allá de las prestaciones que realiza a través de sus órganos- de participar en la satisfacción de necesidades colectivas a nivel prestacional. Aquí hay una manifestación clara de la subsidiariedad en su faz positiva, que normalmente no se advierte por la costumbre de observar solo el inciso segundo del numeral citado cuando se habla de subsidiariedad.

La disposición recién aludida sitúa la Constitución chilena en las antípodas de otras, como la española, que sí permiten aquello que es necesario para la configuración del s.p. (publicatio). El artículo 182.2 de la Constitución española nos parece un ejemplo paradigmático en este sentido, al disponer que "[m]ediante ley se podrá reservar al sector público recursos o servicios esenciales, especialmente en caso de monopolio (...) cuando así lo exigiere el interés general". Como se puede observar, y como también ha sido reconocido en la doctrina española, esta norma nos sitúa frente a una intervención del Estado que implica reserva, es decir, ante la posibilidad de la publicatio. De ahí que se haya sostenido que esta norma permita un "verdadero" s.p., pues reconoce una potestad que "supone la asunción por parte de los poderes públicos territoriales de la titularidad de una categoría genérica de bienes o actividades"119. Asimismo, se reconoce que esta publicatio tendría "carácter genérico o abstracto, en el sentido de que no se proyecta sobre titularidades concretas, sino sobre toda una categoría de bienes o derechos

\footnotetext{
117 Hernández González 2004, 197. Ver también Brewer-Carías 2017, 1-3.

118 SOto Kloss 2002, 48.

119 Ortega Álvarez y Arroyo Jiménez 2018, 837.
} 
o sobre todo un sector de actividad"120. Finalmente, y como corolario de lo dicho, se puede concluir que la reserva que permite el artículo 128.2 "determina la expulsión del sector de actividad reservado del posible ámbito de ejercicio del derecho a la libertad de empresa (...). Los particulares solo podrán acometer la actividad reservada en caso de que se opte por gestionar el servicio indirectamente, y además no lo harán en ejercicio de libertades propias, sino en el de titularidad ajena cuyo ejercicio les habrá sido delegado a través de la oportuna concesión administrativa" ${ }^{121}$. La diferencia con nuestra normativa constitucional es decisiva.

Por lo anterior es que nos parece correcta la conclusión que han formulado ciertos autores respecto a que, al contrario del régimen concesional que dice relación con el dominio público, en lo que se refiere a las concesiones de actividades no existen normas que signifiquen una publicatio, sino que "únicamente contemplan disposiciones que sujetan la actividad o servicios a un régimen concesional"122. A su vez, estas concesiones, en realidad, tienen naturaleza jurídica de autorizaciones, puesto que "ninguna ley ha establecido que esta actividad sea privativa del Estado, sino que, por el contrario, en cumplimiento del artículo 19 número 21 de la Constitución Política de la República, corresponde de suyo a los particulares"123. Respecto a la naturaleza autorizacional de estas concesiones, otros autores han formulado una crítica similar a la confusión conceptual ${ }^{124}$. Asimismo, otro autor ha señalado, a nuestro juicio con razón, que "(...) la denominación concesión de servicio público ha pasado de un criterio de publicatio a uno de ordenatio de las actividades sujetas a concesión"125.

A pesar de lo dicho, hay autores que señalan que nuestra legislación sí contempla actividades económicas reservadas, por lo que los particulares solo podrían acceder a ellas mediante una concesión. El caso que la doctrina nombra con mayor frecuencia es la función de aseo y ornato de la comuna que corresponde a la municipalidad ${ }^{126}$. Este ejemplo nos sirve para ilustrar lo ya expuesto y hacer un par de necesarias precisiones. Veamos.

La tesis de la reserva estatal (publicatio) de la función de aseo y ornato de la comuna, se fundamenta en que el artículo 3 de la ley orgánica de municipalidades confiere esta función a las municipalidades de modo privativo ("funciones privativas"), lo que es sinónimo de que "le es atribuida a ellas de modo exclusivo y excluyente" ${ }^{127}$. Así, al ser exclusivo y excluyente, estaríamos

\footnotetext{
120 ĺdem.

121 Ibíd., 838.

122 Lara Arroyo y García-Huidobro Herrera 2014, 125.

123 lbíd., 127.

124 V.gr. Aróstica Maldonado 2016, 151-152; Vergara Blanco 2004, 46-48; Soto Kloss 2002, 569 570; Moraga Klenner 2019, 154.

125 Cordero Vega 2015, 472.

126 Artículo 3 letra f), Decreto con Fuerza de Ley N 1, de 2006.

127 V.gr. Soto Kloss 2002, 567; Lara Arroyo y García-Huidobro Herrera 2014, 125.
} 
evidentemente ante régimen de intervención que implica reserva de esta actividad de la esfera de la libre iniciativa de los particulares. El problema de esta tesis, sin embargo, es que no es sostenible si se observa a la luz de la historia fidedigna del establecimiento del artículo que contiene la disposición en cuestión y de las distinciones sobre las actividades que caben dentro de la función de aseo y ornato.

Comencemos por decir que el proyecto de ley original no confería esta función de modo privativo. El artículo 2, que contemplaba la función de aseo y ornato, rezaba en su inciso primero: "[c]orrespondera a las municipalidades ejercer las siguientes atribuciones"128. El adjetivo privativo fue introducido en el "Texto sustitutivo Proyecto de Ley", cuyo artículo 3 inciso primero contemplaba una disposición casi idéntica a la actual: "[c]orresponderán a las Municipalidades las siguientes funciones privativas"129. La explicación de este cambio se encuentra en el documento "Informe Comisión Conjunta". En lo que nos concierne, el argumento expuesto para justificar el cambio fue el siguiente:

"Por ende, tanto las funciones como las atribuciones de los municipios, son consideradas materias propias de la Ley Orgánica Constitucional en estudio. Asimismo, se dejó claramente establecido que las funciones de las Municipalidades se dividen entre aquéllas que "privativamente", y con exclusión de otros órganos de la Administración del Estado, les corresponde ejercer (artículo $3^{\circ}$ ), y aquéllas que también debe desarrollar por sí misma, pero en forma "compartida", pues no obsta al ejercicio de funciones similares por parte de otros órganos del sector público (artículo $4^{\circ}$ )"130.

La intención del gobernante, por ocupar la expresión del criterio antes expuesto, no fue reservar la actividad con el fin de excluirla de los particulares, sino que distinguir las potestades con otros órganos de la Administración. De ahí la referencia al artículo 4 que se señala en el documento recién citado, cuyo inciso primero -conforme a la redacción actual- dispone que las municipalidades "podrán desarrollar, directamente o con otros órganos de la Administración del Estado (...)". De hecho, en el documento "Informe Comisión Conjunta" se señala que "(...) cabe hacer presente que la circunstancia de que se trate de funciones "privativas" solo implica que otros órganos de la Administración del Estado están impedidos de asumir, en forma autónoma, tales funciones"131. Esto explica, por lo demás, que la actual redacción de la letra f) del artículo 3 de la ley orgánica de municipalidades contemple, luego de la expresión "[e]l aseo y ornato de la comuna", la siguiente aclaración: "[r]especto a los residuos domiciliarios, su recolección, transporte y/o disposición final corresponderá a las municipalidades, con excepción de las que estén situadas en un área metropolitana y convengan con el respectivo gobierno regional que asuma total o parcialmente estas tareas".

\footnotetext{
128 Historia de la Ley $\mathrm{N}^{\circ} 18.695,11$.

129 Ibíd., 46.

130 lbíd., 87.

131 Ibíd., 87.
} 
Hay también otro argumento para sostener que no nos encontramos ante una actividad respecto de la cual no ha operado la publicatio. Conforme a la letra f) del artículo 3 mencionado y al artículo 25 de la misma ley, podemos distinguir dos tipos de actividades. Por un lado, "[e]l aseo de las vías públicas, parques, plazas, jardines y, en general, de los bienes nacionales de uso público existentes en la comuna" (letra a), artículo 25) y, por otro, "el servicio de extracción de basura" (letra b), artículo 25). Ambas actividades le corresponden a la unidad encargada del medio ambiente, aseo y ornato, aunque la municipalidad también puede concesionarlas (artículo 8). Sin embargo, ninguna de estas actividades está reservadas al Estado de modo que las excluye de la libre iniciativa de los particulares. Respecto de la segunda actividad-extracción de basura-, sin perjuicio de que los usuarios de la comuna deban pagar por este servicio ${ }^{132}$, no existe ningún impedimento jurídico para que estos contraten los servicios de una empresa privada, al margen del servicio municipal o concesionado, con este mismo fin (sin perjuicio de las regulaciones que puedan existir, por ejemplo, desde el punto de vista sanitario). Lo mismo ocurre respecto de la primera actividad -aseo y ornato de bienes públicos-, pues a pesar de que ellos son administrados por la Municipalidad (artículo 5), no hay norma que prohíba, por ejemplo, que una agrupación de vecinos contrate a una empresa particular para el aseo de una plaza que está descuidado. Así, queda claro que no hay publicatio y que la denominación de "concesión" es errada (más adecuada nos parece el vocablo "encomendar" que contempla el artículo 37 de la Ley $\left.N^{\circ} 18.575\right)$.

\section{Conclusiones}

Conforme a lo expuesto, podemos enumerar las siguientes conclusiones:

1. El concepto de s.p. está dirigido a conceptualizar un modo de intervenir que tiene como características fundamentales el ser una definición contingente del legislador $y$, en concreto, significar la reserva estatal de la actividad que se define como s.p..

2. La reserva estatal confiere la titularidad de la actividad que se eleva como s.p. al Estado, de modo tal que la excluye de la esfera de la libre iniciativa de los particulares. El concepto jurídico que significa este fenómeno es el de publicatio.

3. Se ha formulado la tesis de que existiría una nueva noción de s.p., que consistiría en la regulación de actividades económicas que satisfacen necesidades colectivas desarrolladas por particulares. Esta nueva concepción busca conciliar la noción tradicional con un régimen jurídico subsidiario.

4. Esta tesis presenta diversos problemas. Por un lado, realiza un esfuerzo interpretativo que es contrario a las normas básicas de la hermenéutica en el sentido de significar un concepto de un modo incompatible con la noción

132 Artículo 6, Decreto $N^{\circ} 2385$, de 1996. 
original del mismo. Por otro, la noción original es, en sus presupuestos filosóficos, incompatible con el "nuevo" s.p.. El principio de subsidiariedad es contrario a la idea de la reserva de actividades estatales.

5. Nuestra legislación utiliza el concepto s.p. desde un punto de vista orgánico y funcional. Con todo, en ningún caso se usa de un modo que sea compatible con la publicatio, fundamentalmente por el artículo $19 \mathrm{~N}^{\circ} 21$ de la Constitución. A la vez, se comprueba que no hay actividades de s.p. reservadas al Estado, y que la concesión, en este sentido, no opera realmente en nuestro ordenamiento.

\section{Bibliografía citada}

ArAnCIBIA MATtAR, Jaime (2017). La relación jurídica público-privada: iter conceptual, atributos y criterios. En: Sото KLoss, Eduardo [ed.], El derecho Administrativo y la protección de las personas. Libro Homenaje a 30 años de docencia del profesor Ramiro Mendoza en la PUC, Santiago, Ediciones UC, pp. 1-15.

ArIÑo Ortiz, Gaspar (2007). Empresa Pública, Empresa Privada, Empresa de Interés General. Navarra, Editorial Aranzadi, 233 pp.

Ariño Ortiz, Gaspar (2003). Principios de Derecho Público Económico. Modelo de Estado, Gestión Pública, Regulación Económica. Bogotá, Universidad del Externado de Colombia, 933 pp.

ARIÑO OrTIZ, Gaspar (1993). Economía y Estado. Crisis y reforma del sector público. Madrid, Marcial Pons, 422 pp.

Armienta Hernandez, Gonzalo (2013). La privatización de los servicios públicos municipales, una necesidad para la democracia y una realidad. Revista IUS, Vol. 7 N³2, pp. 86-99.

ARÓSTICA MALDONADO, Iván (2016). ¿Qué es "privatizar"? (Una aproximación jurídica). Revista de Derecho Público, Nos 57-58, pp. 239-261.

ARÓstica MALDONADO, Iván (2016). Transferencia de funciones estatales al sector privado en tres contratos administrativos: concesión de servicio público, externalización y sociedad. Revista de Derecho Público, N55/56, pp. 143-160.

Bassols Coma, Martín (1977). Servicio público y empresa pública: reflexiones sobre las llamadas sociedades estatales. Revista de Administración Pública, № 84, pp. 27-60.

Bermúdez Soto, Jorge (2014). Derecho Administrativo General. Santiago, Thomson Reuters, $794 \mathrm{pp}$.

Biblioteca del Congreso Nacional de Chile (s/a). Historia de la Ley № 18.695, Orgánica Constitucional de Municipalidades. Disponible en: https://www.bcn.cl/historiadelaley/ nc/historia-de-la-ley/7546/ [fecha de consulta: 28 enero de 2020].

BreWer-Carias, Allan (2017). Sobre la 'publicatio' en el régimen de la contratación administrativa: las nociones de 'actividades reservas al estado,' 'utilidad pública,' 'interés social,' 'servicio público,' 'dominio público' y 'orden público'. Disponible en: http:// allanbrewercarias.com/wp-content/uploads/2017/10/1200.-conf.-doc.-XVI-FIDA-StoDomingo.pdf [fecha de consulta: 28 enero 2020].

CASSAgne, Juan Carlos (1996). El resurgimiento del servicio público y su adaptación en los sistemas de economía de mercado. (Hacia una nueva concepción). Revista de Administración Pública, N¹40, pp. 95-110.

CASSAGNE, Juan Carlos (2002). Derecho Administrativo. Buenos Aires, Editorial LexisNexis, T II, $622 \mathrm{pp}$.

Cordero VeGA, Luis (2015). Lecciones de Derecho Administrativo. Santiago, Thomson Reuters, $786 \mathrm{pp}$.

CoRdero Vega, Luis (2015). Servicio público imaginario. Disponible en: https://www.elmercurio.com/Legal/Noticias/Analisis-Juridico/2019/01/30/El-servicio-publico-imaginario. aspx?disp=1 [fecha de consulta: 28 enero de 2020]. 
Cordero QuinzaCARA, Eduardo (2013). Sanciones administrativas y mercados regulados. Revista de Derecho (Valdivia), Vol. 26 N¹, pp. 119-144.

Cruz Prados, Alfredo (2006). Ethos y Polis. Bases para una reconstrucción de la filosofía política. Navarra, EUNSA, 442 pp.

Cruz Prados, Alfredo (2009). Filosofía Política. Navarra, EUNSA, 170 pp.

Diccionario de la lengua española, $23^{\circ}$ edición.

Duguit, León (1915). Las transformaciones del Derecho Público (trad. Adolfo Posada y Ramón Jaén). Madrid, Francisco Beltrán, Librería Española y Extranjera, 372 pp.

Evans Espiñeira, Eugenio y Yañez Rebolledo, Eduardo (2017). Derecho y Regulación Económica de la Energía Eléctrica. Santiago, Thomson Reuters, T I, 544 pp.

Fernandez FarReres, Germán (2003). El concepto de servicio público y su funcionalidad en el Derecho Administrativo de la nueva economía. Justicia Administrativa: Revista de derecho administrativo, №18, pp. 7-21.

Fernandez Rodriguez, Tomás-Ramón (1999). Del servicio público a la liberalización. Desde 1950 hasta hoy. Revista de Administración Pública, N¹50, pp. 57-73.

FinNIS, John (1980[2000]). Ley Natural y Derechos Naturales (trad. Cristóbal Orrego Sánchez). Buenos Aires, Abeledo-Perrot, $455 \mathrm{pp}$.

Garcia de Enterria y MarTínez-Carande, Eduardo (1955). La actividad industrial y mercantil de los municipios. Revisa de Administración Pública, Nº17, pp. 87-138.

Garcia de Enterría, Martínez-Carande, Eduardo y Fernández Tomás-Ramón (2006). Curso de Derecho Administrativo. Lima, Editorial Temis, TI, 899 pp.

GarRIDo Falla, Fernando (1994). El concepto de servicio público en Derecho español. Revista de Administración Pública, Nº135, pp. 7-36.

GarRido Falla, Fernando (1953). Las trasformaciones del concepto jurídico de policía administrativa. Revista de Administración Pública, N 11, pp. 11-32.

Gordillo, Agustín (2014). Tratado de Derecho Administrativo y Obras Selectas. Buenos Aires, Fundación de Derecho Administrativo, T II, 752 pp.

Guaita Martorell, Aurelio (1969). Derecho Administrativo Especial. Zaragoza, Librería General, $3^{a}$ edición, 320 pp.

Guzmán Brito, Alejandro (2005). El derecho público y el derecho privado. Revista Persona y Derecho, N²72, pp. 11-21.

HeRnAndez GonzAlez, José Ignacio (2002). Cauces de intervención de la iniciativa económica pública y privada en la nueva ley orgánica de hidrocarburos. Derecho y Sociedad. Revista de estudiantes de Derecho de la Universidad Monteávila, N³, pp. 145-192.

HeRnAndez GonzAlez, José Ignacio (2004). Disciplina jurídico Administrativa de la Libertad Económica. La diatriba actual entre libertad económica y Estado Social. En: BREWER-CARIAS, Allan [AAVV], El principio de legalidad y el ordenamiento jurídico administrativo de la libertad económica: VII Jornadas Internacionales de Derecho Administrativo Allan Randilph Brewer Carías. Caracas, FUNEDA, pp. 179-246.

Herrera Arellano, Hugo (2009). ¿De qué hablamos cuando hablamos del Estado?. Santiago, Instituto de Estudios de la Sociedad, 135 pp.

Jèze, Gastón (1928). Los principios generales del Derecho Administrativo (trad. Carlos García Oviedo). Madrid, Editorial Reus, pp. 563.

JoRnada de PozAS, Luis (1949). Ensayo de una teoría del fomento den el Derecho Administrativo. Revista de estudios políticos, N48, pp. 41-54.

Lara Arroyo, José. y García-Huidobro Herrera, Luis (2014). Sobre el régimen concesional chileno: ¿Podemos hablar de un modelo de concesión?. En: Sото KLoss, Eduardo [coord.], Administración y Derecho. Homenaje a los 125 años de la Facultad de Derecho de la Pontificia Universidad Católica de Chile. Santiago, Thomson Reuters, pp. 89-165.

Letelier Widow, Gonzalo (2015). Dos conceptos de subsidiariedad: el caso de la educación. En: Ortuzar, Pablo [ed.] y Ortuzar, Santiago [coord.], Subsidiariedad. Más allá del Estado y del mercado. Santiago, Instituto de Estudios de la Sociedad, pp.113-138.

MAnent, Pierre (2016). Curso de Filosofía Política. Santiago, Instituto de Estudios de la Sociedad, $336 \mathrm{pp}$.

Mılıan-Puelles, Antonio (2000). Persona humana y justicia social. México, Minos, 161 pp. 
Moraga Klenner, Claudio (2019). Contratación administrativa. Santiago de Chile, Thomson Reuters, 613 pp.

Ortega Álvarez, Luis y Arroyo Jiménez, Luis (2018). Artículo 128. En: Rodríguez-Piñero, Bravo Ferrer, Miguel y Casas BaAmonde, María [coord.], Comentarios a la Constitución Español. Madrid, Fundación Wolters Kluwer, Boletín Oficial del Estado, T II, pp. 837-841.

Orrego Sanchez, Cristóbal (2019). Derecho: Conceptos Fundamentales. Santiago, Ediciones del Círculo de Santiago, 234 pp.

Orrego Sánchez, Cristóbal (1989). Acerca del Derecho en la unidad de las ciencias y de las artes. Revista Chilena de Derecho, Vol. 16 N¹, pp. 67-97.

Platon (1969). Obras Completas. Madrid, Editorial Aguilera, 1741 pp.

Pierry Arrau, Pedro (2017). El servicio público en Chile. En: Cordero Quinzacara, Eduardo [coord.], Derecho Administrativo. Obra Reunida. Valparaíso, Ediciones Universitarias de Valparaíso, pp. 105-114.

Rebollo, Luis Martín (2008). Sobre el nuevo concepto de servicio público en Europa y sus posibles implicaciones futuras. En: Cienfuegos Salgado, David y Rodriguez Lozano, Luis [coord.], Actualidad de los servicios públicos en Iberoamérica. Ciudad de México, Universidad Nacional Autónoma de México, pp. 355-382.

Rodriguez-Arana Muñoz, Jaime (2013). Sobre Las Transformaciones del Derecho Público, de León Duguit. Revista de Administración Pública, N 190, pp. 61-100.

Rojas Calderón, Christian (2014). La categoría jurídica de los "servicios privados de interés público. El caso de la junta de vigilancia de los ríos. Revista Chilena de Derecho, Vol. $41 \mathrm{~N}^{\circ} 1$, pp. 171-204.

SANTOFImio GAmboA, Jaime (2011). León de Duguit y su doctrina realista, objetiva y positiva del Derecho en las bases del concepto de servicio público. Revista digital de Derecho Administrativo, N5, pp. 43-86.

Silva Cimma, Enrique (1995). Derecho Administrativo Chile y Comparado. El servicio público. Santiago, Editorial Jurídica de Chile, 323 pp.

Sото KLoss, Eduardo (2012). Derecho Administrativo. Temas Fundamentales. Santiago, AbeledoPerrot-Thomson Reuters, $966 \mathrm{pp}$.

URBINA Molfino, Francisco (2005). El principio de subsidiariedad, sus fundamentos y su función en una sociedad democrática. Derecho y Humanidades, N 11, pp. 325-335.

Valdivia Olivares, José Miguel (2018). Manual de Derecho Administrativo. Valencia, Tirant Lo Blanch, 448 pp.

Vergara Blanco, Alejando (2004). El nuevo servicio público abierto a la competencia: de la publicatio al libre acceso. Coherencia de las viejas técnicas concesional y autorizacional. Revista de Derecho Administrativo Económico, №12, pp. 33-49.

\section{Normas citadas}

Constitución Política de la República.

Decreto con Fuerza de Ley $N^{\circ} 1 / 19.653$, que fija el texto refundido, coordinado y sistematizado de la ley $N^{\circ} 18.575$, Orgánica Constitucional de bases generales de la Administración del Estado. Diario Oficial, 17 noviembre 2001.

Ley N ${ }^{\circ}$ 18.575, Orgánica Constitucional de bases generales de la Administración del Estado. Diario Oficial, 25 diciembre 1986.

Ley $N^{\circ} 19.253$, que establece normas sobre protección, fomento y desarrollo de los indígenas, y crea la Corporación nacional de desarrollo indígena. Diario Oficial, 5 octubre 1993.

Decreto con Fuerza de Ley $N^{\circ} 1$, que Fija el texto refundido, coordinado y sistematizado de la ley N 18.695, Orgánica Constitucional de Municipalidades. Diario Oficial, 26 julio 2006.

Decreto con Fuerza de Ley $N^{\circ} 4 / 20.018$, que fija el texto refundido, coordinado y sistematizado del Decreto con Fuerza de Ley N 1, de Minería, de 1982, ley general de servicios eléctricos, en materia de energía eléctrica. Diario Oficial, 5 febrero 2007. 
Decreto con Fuerza de Ley $N^{\circ} 1$, que fija texto refundido, coordinado y sistematizado del decreto ley $N^{\circ} 2.763$, de 1979 y de las leyes $N^{\circ} 18.933$ y N² 18.469. Diario Oficial, 14 abril 2006.

Decreto $N^{\circ} 2385$, que fija texto refundido y sistematizado del decreto ley $N^{\circ} 3.063$ de 1979, sobre rentas municipales. Diario Oficial, 20 noviembre 1996.

Decreto con Fuerza de Ley $N^{\circ} 2$, que dispone la reestructuración y fija las funciones de la Dirección del Trabajo. Diario Oficial, 29 septiembre 1967.

Decreto con Fuerza de Ley $N^{\circ} 36$, normas que se aplicarán en los convenios que celebren los Servicios de Salud. Diario Oficial, 27 diciembre 1980.

Decreto supremo $N^{\circ} 67$, Ministerio de Salud, que aprueba reglamento para ejercer objeción de conciencia según lo dispuesto en el artículo 119 ter del código sanitario. Diario oficial, 23 octubre 2018.

\section{Jurisprudencia citada}

Sentencia TC Rol No 1295 (2008): Tribunal Constitucional, 31 diciembre 2008.

Sergio Carrasco Delgado con Isapre Consalud S.A. (2010): Corte Suprema, 28 enero de 2011.Sentencia TC Rol No2337 (2013): Tribunal Constitucional, 1 octubre 2013.

Dictamen No 11.781 (2018): Contraloría General de la República, 9 de mayo de 2018.

Dictamen No 24.216 (2018): Contraloría General de la República, 27 de septiembre de 2018.

Sentencia TC Rol No 5572 (2018): Tribunal Constitucional, 31 octubre 2018. 